\title{
Keeping Human Rights on the Bioethics Agenda
}

\author{
JOSEPH C. D'ORONZIO
}

The ideal of universal human rights is arguably the most potent moral concept marking the modern world. Its accelerated fruition in the last half of the twentieth century has created a powerful political force, laying the groundwork for future generations to extend and apply. Whereas anything resembling international legal status for human rights had to wait for the post-Nazi era, the bold proclamations of the Universal Declaration of Human Rights (UDHR, 1948) loosened a revolutionary force with endless potential for application to the full range of human endeavors. The roots of this movement can be traced to each and every era in which the vulnerable and powerless sought justification to oppose arbitrary domination. Its roots are, therefore, deep and wide.

At the same time, we must acknowledge that this breadth encompasses the full range of cultures gathered under the Declaration's protection, leaving its interpretation, in many key areas, continually problematic. Its origins are clearly political, but as the human rights revolution flourishes, as the webs of political power weaken, and as globalism finds its full expression, the range of application for human rights expands. The 30 articles of the UDHR catalogue a full range of civil, political, economic, and social rights "... of all members of the human family [which are] the foundation of freedom, justice, and peace in the world."
Until this vision is realized across the range of human activities and in the context of cultural diversity, there is work to be done.

The human rights community, a distinctive feature of the twentieth century, is still in a formative stage, developing these applications across the range of human activity. Its relationship with health and medical professionals is a case in point. It has not, to date, developed sufficient connections, but pressured by the international AIDS pandemic and under the inspired leadership of Jonathan Mann, there has been some notable collaboration in the area of global public health. Indeed, it was Mann's special mission to facilitate communication between these communities. Following the Third World Congress of Bioethics in 1996, a symposium on "The Globalization of Bioethics: International Human Rights and the Health Professions" provided the opportunity for members of the diverse disciplines of international law, medicine, and public health to focus on the unifying global theme of human rights. ${ }^{1}$ It succeeded in placing this constellation of disciplines, commonly isolated, into novel juxtaposition and sought to add a fourth disciplinary partner to the team: bioethics. It was after that symposium that Jonathan and I agreed to collaborate and coedit a collection of essays for $C Q$ to give voice to this unified vision. The central question was, 
what does ethics have to offer to the social mission of international health and human rights?

Placing human rights on the bioethics agenda is, in truth, "old business." For, as this present collection of essays and observations makes clear, there have been intrinsic conceptual and historical links between the two. Both the 1996 symposium and this collection of essays have in common the objectives to make the connections explicit and to expand their mutual relevance.

The reconstruction of this relationship is here presented in three aspects, the theoretical, the applied, and future directions. The first two essays, one by Robert Baker and the second by Lori P. Knowles, introduce the subject in historical and conceptual terms, respectively, providing a basis for appreciating the connection between traditional human rights concerns and the development of bioethics. In the following three essays by Lawrence $\mathrm{O}$. Gostin, M. Gregg Bloche, and your editor, applications of positive human rights are explored in the areas of mental health, the conflict between professional ethics and state power, and the expansion of access to care as an extension of patients' rights. Finally, David Thomasma explores the future ramifications of a union of bioethics and human rights on the international stage. I wish to thank these scholars for their willingness to craft their essays to the larger theme, which has made our labors a truly cooperative venture. They have contributed a great deal to my understanding of human rights. It has been a pleasure to work with them.

The contribution of Jonathan Mann to this publication is recognized in our dedication of it to him. His role, moreover, in the development of the range of issues addressed by this collection of essays is so extensive and substantive that it is deserving of a review in lieu of the essay he might have written. An introductory essay, "The Integration of Health and Human Rights: An Appreciation of Jonathan M. Mann," outlines the key ideas and special perspective that Mann contributed to understanding the complex relationships between global health, human rights, and bioethics. His ideas emerged from a combination of a deep intellectual and moral commitment along with the practical imperatives of his engagement in mobilizing the World Health Organization's assault on AIDS in the mid-1980s. The maturation of his recent thinking led him to recognize a natural connection with ethics as a source of core concepts to better articulate the societal values that guide both the meaning of health and the meaning of human rights. His was an integrative perspective, much needed in an era of dispersed professional commitments in response to new technologies, new discoveries, and new challenges to health.

Robert Baker, in "Reconciling Bioethics and Human Rights: Some Historical Reflections," takes up the challenge of tracing the parallel development of the two movements and the basis for their divergent paths. His is a philosophical analysis of the concepts placed in a postWorld War II historical setting. It finally argues that bioethics would be better off if it reconciled its principalism with human rights theory.

Lori P. Knowles, in her essay "The Lingua Franca of Human Rights and the Rise of a Global Bioethic," takes the understanding of this connection a step further by identifying key current global challenges in health that require bioethical analyses that would need to go beyond the Anglo-American tradition of bioethics. She suggests that the human rights framework, grounded in and defined by international conventions as well as consisting of transcending principles, offers a possible common ground. 
Turning to the specific application of the human rights perspective, in "Beyond Moral Claims: A Human Rights Approach in Mental Health," Lawrence O. Gostin seeks to explain how we might use the language and doctrines of international human rights to attain a dignified, humane, and legal basis for a right to mental health. This construction of a meaningful set of positive rights to mental health requires a marriage of the moral justification provided by bioethics and the legally enforceable standards found in international human rights law.

With "Caretakers and Collaborators," M. Gregg Bloche extends the application of professional ethics concerns into the realm of human rights, examining the troubling issue of professional complicity in human rights violations. He makes a convincing argument that there is little ethical guidance at the margins of healthcare professional behavior in the service of state objectives. Tracing both the insidious and the gross violations of the trust of vulnerable persons, Bloche urges a level of professional ethics that draws from the value framework of human rights activism.

Joseph C. d'Oronzio's "A Human Right to Healthcare Access: Returning to the Origins of the Patients' Rights Movement" addresses the current "patients' rights" debate through the lens of healthcare ethics and human rights. It builds on the observation that the concern with the rights of consumers of managed care distracts from a more fundamental concern with the rights of those without access to any care. Providing an account of the origins of the patients' rights movement of the late 1960s, he argues that, at its source, "patients' rights" was a movement for guaranteed healthcare as a positive human right to which we should return.

In the final paper, "Proposing a New Agenda: Bioethics and International
Human Rights," David Thomasma argues that both bioethics and human rights, to benefit one another, must incorporate the strength of each discipline while avoiding the pitfalls of relativism on the one hand and absolutism on the other. He suggests a series of rules for dialogue and research that can enhance current bioethics and move it to the next level of international inquiry and discussion.

\section{Call for Agenda Items}

Taken together, we hope these essays provide a model for understanding the relationships that exist between the human rights concept and bioethical concerns. We also hope that they suggest ways to make further applications. For in exploring these relationships, we aimed less at the definitive, comprehensive, or complete account and more to the conceptually suggestive. Important areas of application are not included. Healthcare in correctional facilities, for example, involves a population that is marginalized, vulnerable, and isolated for the purpose of punishment. Addressing the health status of inmates, through a bioethical and public health perspective, is a human rights issue worthy of exploration. Women's health is another. Clinical issues, research issues, and the range of human rights protection for women subjected to oppressive and dangerous cultural practices, be they genital mutilation or domestic violence, all fall within this purview. Another example is the biotechnology of genetic research and engineering. If the "human community" includes its genetic material, are not the processes of research and utilization of this material, as a feature of the future health and well-being of the community, appropriate subjects of human rights inquiry? 
For these and other similar topics, Note we issue a call for future papers to sustain human rights on the bioethics agenda.

Note: Health Policy Watch is intended to be a forum for readers interested in themes of health and public policy as they relate to bioethics and social values. We welcome your ideas, suggestions, and guest columns. Submit them to the HPW section editor, Joseph d'Oronzio, care of CQ.

1. The sponsors of the symposium were: Dan Wikler, for the International Association of Bioethics (IAB); Kari Hannibal and Vince Iacopino for Physicians for Human Rights (PHR); Jack Bryant, for the Council of International Organizations of Medical Societies (CIOMS); M. Gregg Bloche for the Georgetown-Johns Hopkins Joint Program in Law and Public Health; and Jonathan M. Mann for the Francois-Xavier Bagnoud Center for Health and Human Rights, Harvard School of Public Health. 